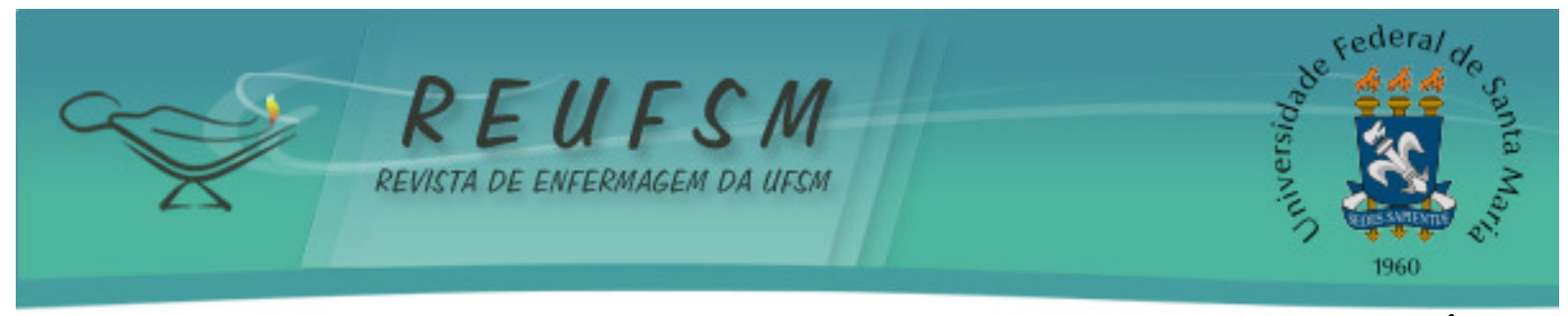

RELATO DE EXPERIÊNCIA

\title{
TERAPIA POR PRESSÃO NEGATIVA ARTESANAL COMO ADJUVANTE NA AUTOENXERTIA CUTÂNEA EM TRAUMA ORTOPÉDICO
}

\section{ARTISANAL NEGATIVE PRESSURE THERAPY AS AN ADJUVANT TO AUTOGRAFT SKIN IN ORTHOPEDIC TRAUMA}

\section{TERAPIA DE PRESIÓN NEGATIVA ARTESANAL COMO COMPLEMENTO DEL AUTOINJERTO DE PIEL EN TRAUMA ORTOPÉDICO}

Reginaldo Passoni ${ }^{1}$ Jéssica Rosin ${ }^{2}$

Daniela Patrícia Tres ${ }^{3}$ Roger Rodrigues Peres ${ }^{4}$ Danielli Piatti Carvalho ${ }^{5}$ Lili Marlene Hofstatter ${ }^{6}$

Doi: $10.5902 / 2179769215981$

RESUMO: Objetivo: descrever a experiência com o uso da terapia por pressão negativa artesanal como adjuvante na autoenxertia cutânea em trauma ortopédico. Método: relato de experiência fundamentado na vivência prática ao manejo clínico de ferida complexa em paciente acometido por trauma ortopédico. Realizaram-se avaliação inicial, desbridamento enzimático, desbridamento cirúrgico e curativos com terapia por pressão negativa. Resultados: a utilização da terapia subatmosférica de maneira artesanal apresentou resultados positivos significativos, semelhante àqueles obtidos com a utilização de produtos industrializados, pois possibilitou o reparo tecidual do ferimento complexo e viabilizou a autoenxertia com sucesso. Considerações finais: a terapia por pressão negativa artesanal apresenta boa efetividade e eficácia, tornando-se, uma opção para instituições de saúde de pequeno e médio porte, cujos recursos financeiros não favorecem a aquisição de modelos comerciais específicos para tal finalidade.

Descritores: Ferimentos e lesões; Técnicas de fechamento de ferimentos; Tratamento de ferimentos com pressão negativa; Enfermagem.

ABSTRACT: Aim: to describe the experience with the execution of artisanal negative pressure therapy as an adjunct to skin autograft in orthopedic trauma. Method: report based on practical experience on clinical management of complex wound in patients with an orthopedic trauma. There were initial assessment, enzymatic debridement, surgical dressings and debridement with negative pressure therapy. Results: the use of subatmospheric therapy of artisanal way showed significant positive outcomes, similar to

\footnotetext{
1 Enfermeiro, Residente em Gerenciamento de Enfermagem em Clínica Médica e Cirúrgica, Universidade Estadual do Oeste do Paraná, Cascavel, Paraná, Brasil. E-mail: regi-pas@hotmail.com

${ }^{2}$ Enfermeira, Residente em Gerenciamento de Enfermagem em Clínica Médica e Cirúrgica, Universidade Estadual do Oeste do Paraná, Cascavel, Paraná, Brasil. E-mail: rosin.je@gmail.com

3 Enfermeira, Residente em Gerenciamento de Enfermagem em Clínica Médica e Cirúrgica, Universidade Estadual do Oeste do Paraná, Cascavel, Paraná, Brasil. E-mail: danielapatriciatres@gmail.com

4 Enfermeiro, Residente em Gerenciamento de Enfermagem em Clínica Médica e Cirúrgica, Universidade Estadual do Oeste do Paraná, Cascavel, Paraná, Brasil. E-mail: roger_rrp@yahoo.com.br

${ }^{5}$ Enfermeira, Mestre em Biociências e Saúde, Coordenadora da Comissão de Curativos, Hospital Universitário do Oeste do Paraná, Cascavel, Paraná, Brasil. E-mail: danielli_pc@hotmail.com

${ }^{6}$ Enfermeira, Mestre em Enfermagem, Professora do Programa de Residência em Enfermagem, Universidade Estadual do Oeste do Paraná, Cascavel, Paraná, Brasil. E-mail:Im_hofstatter@yahoo.com.br
} 


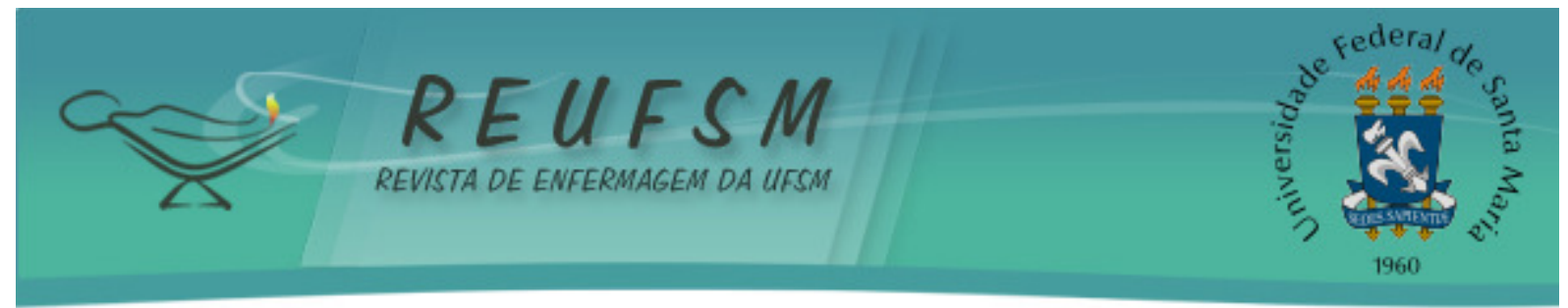

those obtained with the use of commercialized products. It enabled the repair of complex tissue injury and helped autograft successfully. Final Remarks: the artisanal negative pressure therapy shows good effectiveness and efficiency, making it an option for health institutions to small and medium businesses whose financial resources do not support the acquisition of specific business models for this purpose.

Descriptors: Wounds and injuries; Wound closure techniques; Negative-pressure wound therapy; Nursing.

RESUMEN: Objetivo: describir la experiencia con el uso de terapia de presión negativa como un complemento de autoinjerto de piel en trauma ortopédico. Método: relato basado en la experiencia práctica en el manejo clínico de la herida compleja en pacientes afectados por un trauma ortopédico. Fue realizada una evaluación inicial, desbridamiento enzimático y quirúrgico y apósitos con terapia de presión negativa. Resultados: el uso de la terapia subatmosférica de manera artesanal presentó resultados significativos, similares a los obtenidos con el uso de productos comerciales, que permitieron a la reparación de la lesión del tejido complejo y posibilitaron el autoinjerto con éxito. Consideraciones finales: la terapia de presión negativa muestra una buena eficacia y eficiencia. Es una opción para las instituciones de saludes pequeñas y medianas cuyos recursos financieros no favorecen la adquisición de modelos de negocio específicos para este fin.

Descriptores: Heridas e traumatismos; Técnicas de cierre de heridas; Terapia de presión negativa para heridas; Enfermería.

\section{INTRODUÇÃO}

A terapia por pressão negativa consiste na aplicação de pressão subatmosférica no leito de feridas estagnadas nas fases de inflamação e proliferação, e ainda em feridas que estão em estado agudo; com o objetivo de promover a drenagem do excesso de fluidos, reduzir a população bacteriana e o edema, aumentar o fluxo sanguíneo local e estimular a formação do tecido de granulação. ${ }^{1-2}$ Desse modo, essa modalidade de tratamento pode ser recomendada para ampla variedade de lesões, tais como aquelas provenientes de pés diabéticos, úlcera de pressão, trauma, queimadura e fasceíte necrotizante, a fim de acelerar o processo de cicatrização. ${ }^{3}$

A referida terapia tem como método a aplicação de uma esponja estéril na superfície ou cavidade da ferida, seguida pela instalação de um envoltório plástico adesivo sobre a esponja, que gera um sistema selado, onde então é aplicada uma pressão subatmosférica (entre $50 \mathrm{mmHg}$ e $125 \mathrm{mmHg}$ ) por meio de um tubo rígido conectado a um aspirador, de forma contínua ou em ciclos. ${ }^{1}$

Neste sentido, diversas instituições têm desenvolvido e aderido à realização de técnicas artesanais, sendo possível obter resultados igualmente positivos, como a recuperação das lesões num menor período de tempo, redução dos índices de infecção no sítio da ferida e dos gastos financeiros globais com o tratamento. ${ }^{2-3}$

Em trabalho realizado num hospital universitário da cidade de Belo Horizonte (MG), ${ }^{4}$ profissionais destacam o uso da terapia à vácuo, realizada artesanalmente, como adjuvante no processo de fechamento progressivo da cavidade abdominal em pacientes submetidos à laparostomia. Os autores do referido estudo apresentam que, dentre os resultados positivos alcançados com a técnica pode-se salientar a boa contenção das vísceras abdominais, além do controle do volume de exsudatos e do edema local. ${ }^{4}$

Cabe ressaltar, que o tratamento de feridas deve aliar conhecimentos, habilidades e atitudes por parte dos profissionais envolvidos e, assim, se efetivar de maneira segura e 


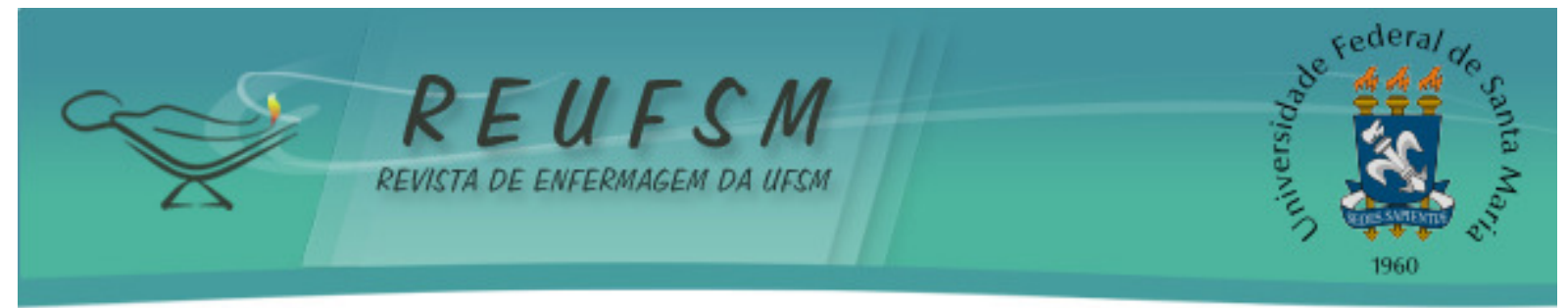

qualificada. Nessa direção, a enfermagem se destaca por ser a categoria de profissionais da saúde referencial no que tange à avaliação e conduta perante aos mais variados tipos de feridas, seja no âmbito intra ou extra-hospitalar. ${ }^{5}$

Dessa forma, torna-se importante que seja apresentada à comunidade acadêmicocientífica, especialmente por meio de relatos de experiências, a importância do papel da Enfermagem como ciência detentora de saberes que pode contribuir com a recuperação e reabilitação de pacientes acometidos por feridas complexas.

Face ao apresentado, este estudo tem como objetivo descrever a experiência com o uso da terapia por pressão negativa artesanal em um Hospital Universitário, como adjuvante na autoenxertia cutânea em trauma ortopédico.

\section{MÉTODO}

0 artigo trata-se de um relato de experiência, o qual apresenta os resultados obtidos frente às condutas práticas de profissionais de Enfermagem, estabelecidas para o manejo clínico-assistencial de um trauma ortopédico complexo. O período de condução do caso ocorreu entre 15 de março a 03 de maio de 2014. Os profissionais envolvidos diretamente no processo foram: dois residentes de Enfermagem, uma enfermeira preceptora e um paciente (acometido com trauma ortopédico complexo). Salienta-se, que o cenário das atividades foi a unidade de internação clínico-cirúrgica em neurologia e ortopedia de um Hospital Universitário público do Paraná (PR), Brasil.

0 processo de cuidado ocorreu a partir dos seguintes acontecimentos: avaliação inicial (realizada pela enfermeira preceptora - a qual é membro da comissão de curativos do hospital); aplicação de produto sobre o trauma para desbridamento enzimático; desbridamento cirúrgico (realizado pela equipe médica responsável pelo paciente); realização de curativos com o uso da terapia por pressão negativa, os quais foram realizados pela enfermeira da comissão de curativos com apoio de residentes em enfermagem da instituição; avaliações subsequentes (realizadas a partir da análise observacional, diária, quanto aos aspectos de sujidade, dor local e/ou perda do vácuo).

No que tange à limpeza/antissepsia da lesão, foram utilizadas solução fisiológica à $0,9 \%$ associada ao uso de solução com tensoativos de digliconato de clorexidina à $2 \%$. Para instalação do curativo por meio da pressão negativa foram necessários os seguintes materiais: esponja de poliuretano com cinco centímetros de espessura, estéril; sonda flexível de silicone; papel filme transparente, adesivo e estéril; prolongamento de silicone (utilizado em sistemas de aspiração); frasco coletor de sistema de aspiração (com pressão contínua de média variada entre 50 e $125 \mathrm{mmHg}$, a qual era avaliada diariamente). A partir da instalação do curativo por pressão negativa, procedeu-se a troca diária durante as duas primeiras semanas de uso, devido à alta concentração de fluídos drenados e saturação da cobertura primária (esponjas de poliuretano). Após esse período a troca ocorreu de acordo com a necessidade, respeitando-se o limite máximo de cinco dias para permanência com o mesmo curativo, procedendo-se sua troca ao final deste prazo.

Tendo em vista que a instituição possui a comissão de curativos, considera-se que a seleção do paciente se deu por conveniência, uma vez que as avaliações e condutas de enfermagem ocorreram perante a necessidade de cuidado especializado, no que diz respeito à lesão complexa que o paciente apresentava. 0 acompanhamento aconteceu através de imagens e com fichamento realizado por meio da descrição do aspecto geral da ferida e das condutas tomadas em cada avaliação, sendo estes dados inseridos na evolução de enfermagem realizada pelo membro da comissão de curativos no prontuário eletrônico do paciente. 


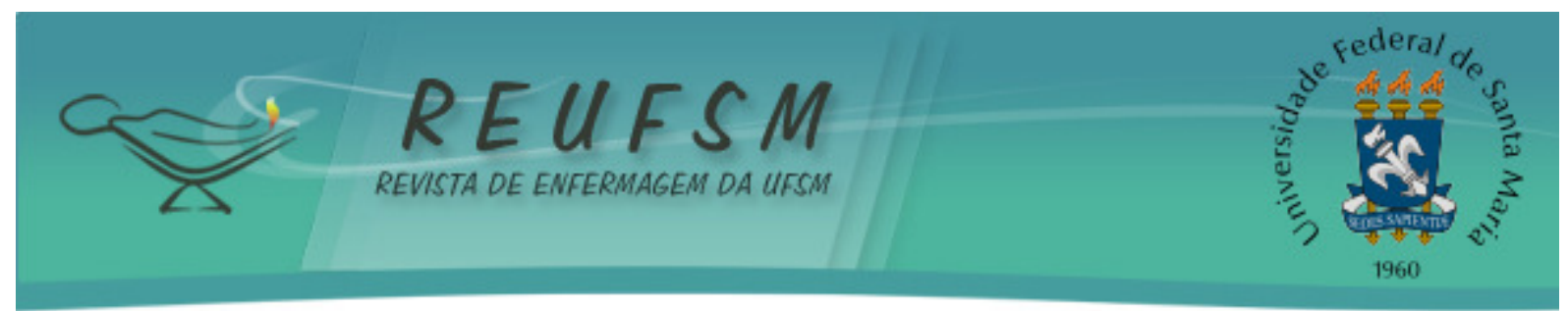

Diante da natureza deste estudo, o qual representa uma descrição narrativa da experiência profissional vivenciada perante o manejo de um caso relativo a práxis da Enfermagem Médico-cirúrgica, julgou-se não haver necessidade de aprovação no Comitê de Ética em Pesquisa. Contudo, ressalta-se que em respeito aos aspectos éticos e legais das pesquisas com serem humanos não se apresentou, em nenhum momento, qualquer dado que pudesse revelar a identificação do paciente. Ademais, houve solicitação verbal de autorização para acompanhamento da evolução da ferida por meio de imagem e, posteriormente, uso das mesmas na produção deste trabalho científico. Outrossim, os autores assinaram termo de comprometimento e responsabilização, declarando que o uso das imagens seria única e exclusivamente para fins acadêmico-científicos.

\section{RESULTADOS}

\section{Descrição do Caso}

Paciente com 71 anos de idade, sexo masculino, cor branca, brasileiro, aposentado, com ensino fundamental incompleto. Admitido no Pronto Socorro (PS) de um Hospital Universitário do sul do Brasil, no mês de março de 2014, e encaminhado pelo Serviço de Atendimento Móvel de Urgência (SAMU) por trauma decorrente de queda de árvore sobre região abdominal e membro inferior esquerdo (MIE).

$\mathrm{Na}$ avaliação inicial, referiu dor de grande intensidade em região não especificada de MIE. À inspeção do membro, evidenciou-se lesão complexa (laceração) por esmagamento do tornozelo esquerdo e fratura, após exame radiológico.

No segundo dia de internamento hospitalar, a equipe médica procedeu à realização de redução cruenta da fratura (osteossíntese tibial) com reconstrução de partes moles e desbridamento de tecidos desvitalizados. No terceiro dia, realizado curativo em Ferida Operatória (FO) com óleo vegetal (Triglicérides de Cadeia Média - TCM), cobertura não aderente estéril, chumaço estéril e envolvimento do membro com atadura de crepe em tala gessada.

No quarto dia, a FO apresentava-se com exsudato purulento em moderada quantidade, odor fétido, tecidos desvitalizados, lesões bolhosas em maléolo externo e dorso do pé, hiperemia e calor local. Assim, solicitou-se parecer de membro da comissão de curativos do hospital, para avaliação e conduta quanto ao tratamento da lesão, a qual passou a acompanhar e realizar as trocas de curativos do paciente. Paralela à solicitação feita à comissão de curtativos, a equipe médica conversou com os familiares do paciente sobre a gravidade do quadro, expondo a possibilidade de amputação do membro lesado.

Após a primeira avaliação feita pela comissão de curativos, procedeu-se à aplicação de hidrogel associado à alginato de cálcio e sódio (para desbridamento enzimático) e carvão ativado para neutralização de odores (Figura 1). 

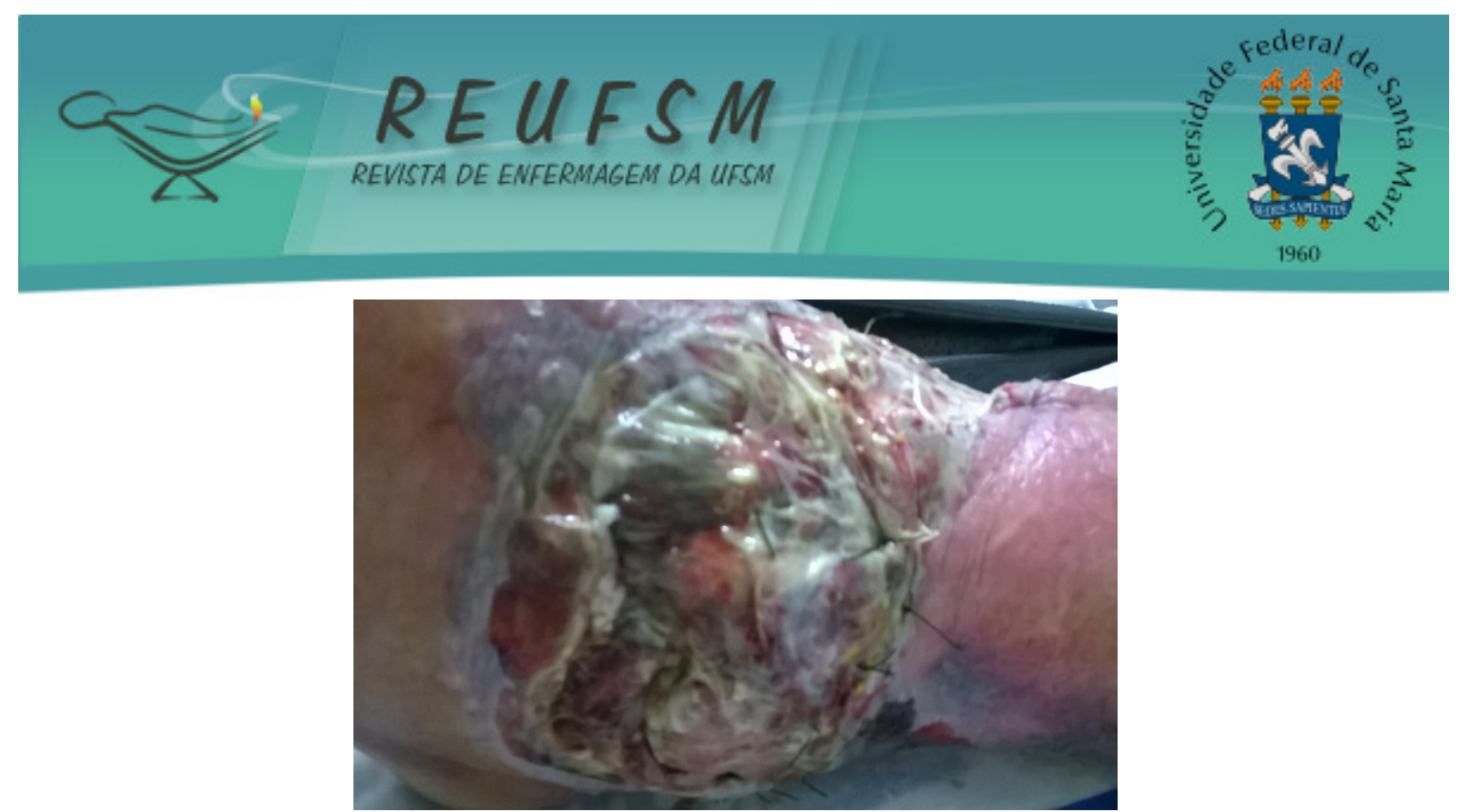

Figura 1 - Ferida operatória no $8^{\circ}$ dia de internação, em uso de alginato de cálcio e sódio 31/03/2014. Cascavel-PR, 2014.

No sétimo dia de internação hospitalar, a ferida ainda apresentava exsudato purulento em grande quantidade e necrose tecidual importante; porém, com diminuição do odor. A partir de então, procedeu-se somente com a aplicação de hidrogel com alginato de cálcio e sódio até o $16^{\circ}$ dia de internação; no $11^{\circ}$ dia, o paciente foi encaminhado para novo desbridamento cirúrgico e coleta de material para cultura, realizados pela equipe médica.

Após remoção completa do tecido necrótico - por meio de desbridamento cirúrgico e enzimático- a lesão apresentava extensa área com exposição de músculos, fascias e tendões. Neste sentido, após oito dias de desbridamento, optou-se pela terapia por pressão negativa (Figura 2) para regeneração dos tecidos, especialmente para cobertura do tecido tendinoso, sem a qual não seria possível proceder à autoenxertia cutânea, considerando que a área receptora, além de preparada, deve apresentar vascularização suficiente para viabilizar a nutrição e integração do enxerto. ${ }^{5}$

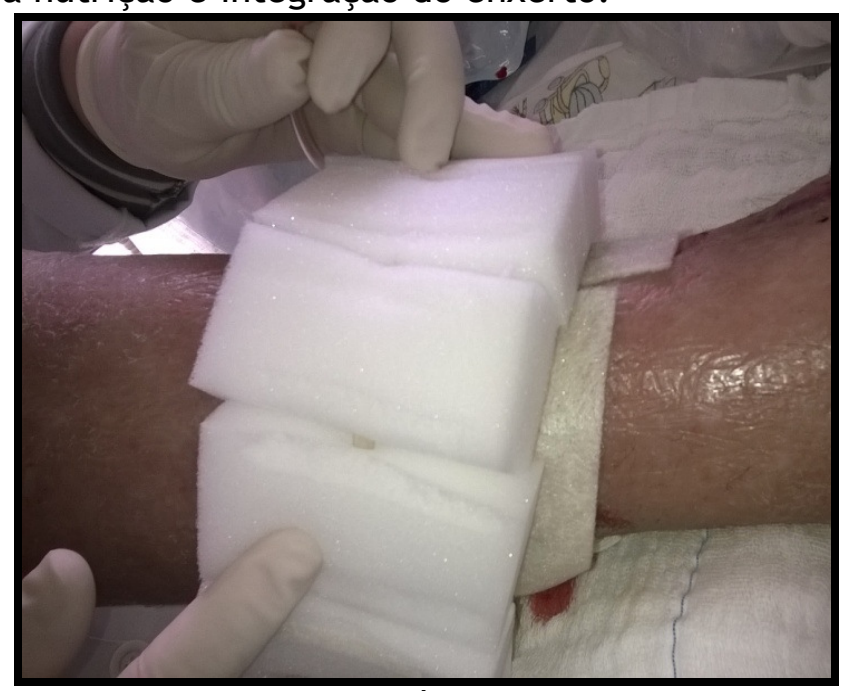

Figura 2 - Terapia por pressão negativa- método artesanal. Cascavel-PR, 2014.

Após uma semana da instalação de curativo por pressão negativa, verificou-se importante granulação dos tecidos. No $16^{\circ}$ dia em uso deste método terapêutico o paciente foi avaliado pelo cirurgião plástico, que em consenso com membro da comissão de curativos, optou pela realização da terapia por pressão negativa por mais 15 dias antes do 


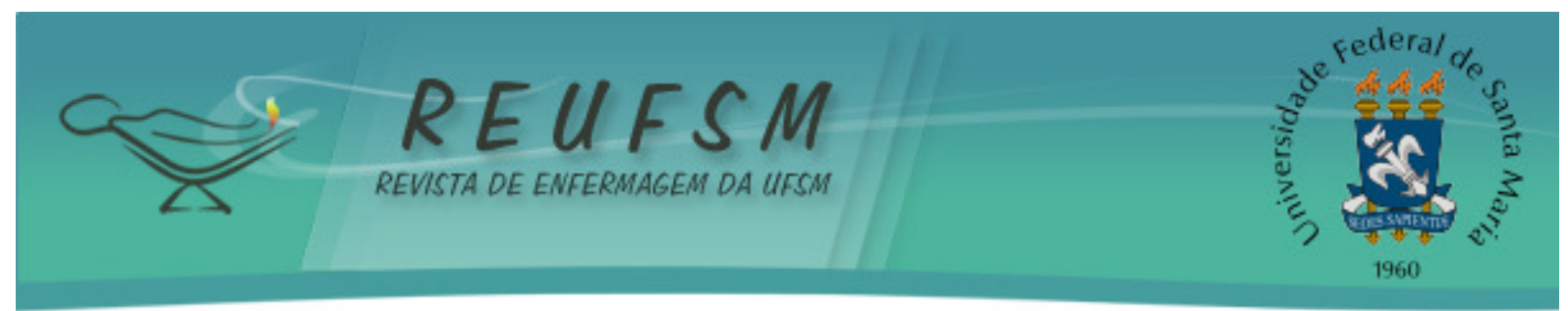

procedimento cirúrgico para enxertia, devido a não cobertura total do tecido tendinoso (Figura 3).

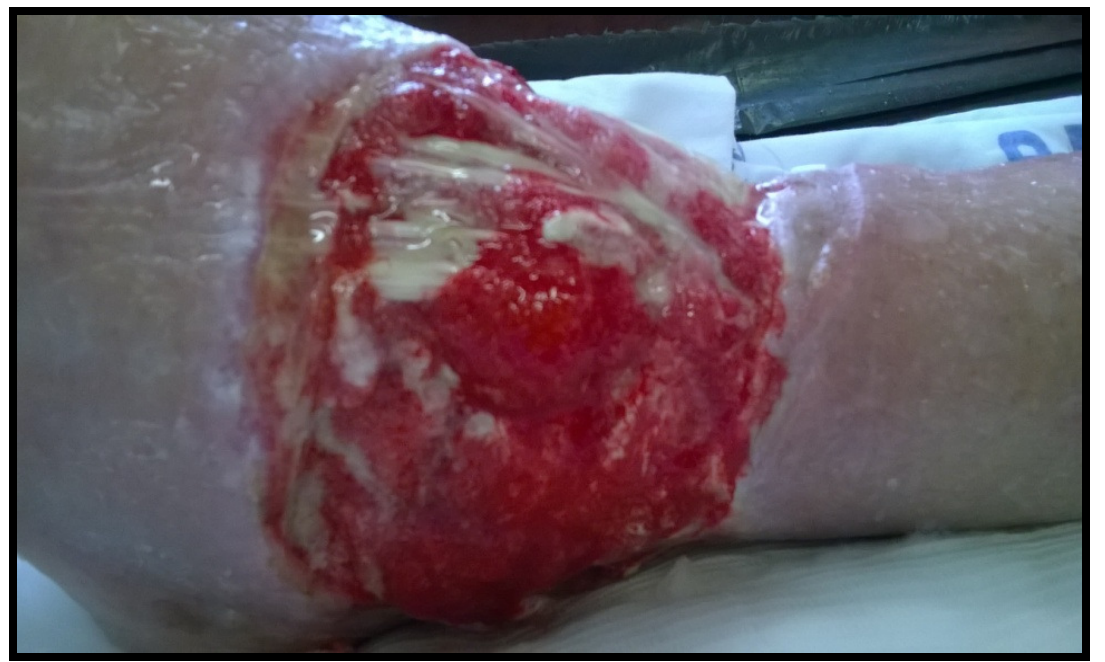

Figura 3 - Ferida operatória, após 18 dias em uso da Terapia por pressão negativa 18/04/2014. Cascavel-PR, 2014.

No $33^{\circ}$ dia de uso da terapia foi possível verificar a presença de tecido de granulação por toda extensão da área lesionada (Figura 4), restando poucas áreas de exposição de tendões.

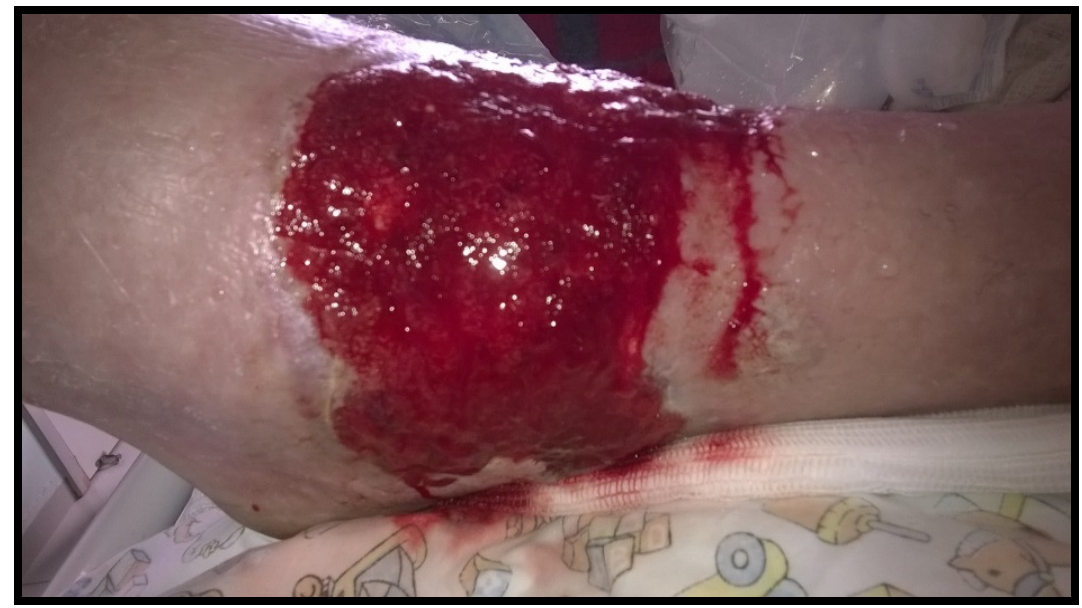

Figura 4 - Ferida operatória após 47 dias em uso da Terapia por pressão negativa 17/05/2014. Cascavel-PR, 2014.

A reavaliação da equipe de cirurgia plástica foi realizada no $35^{\circ}$ dia de uso do curativo a vácuo, sendo que nesta avaliação foi agendada a data para enxertia, pois a ferida apresentava as condições necessárias para o procedimento. A figura abaixo apresenta a área lesionada após a autoenxertia cutânea. 

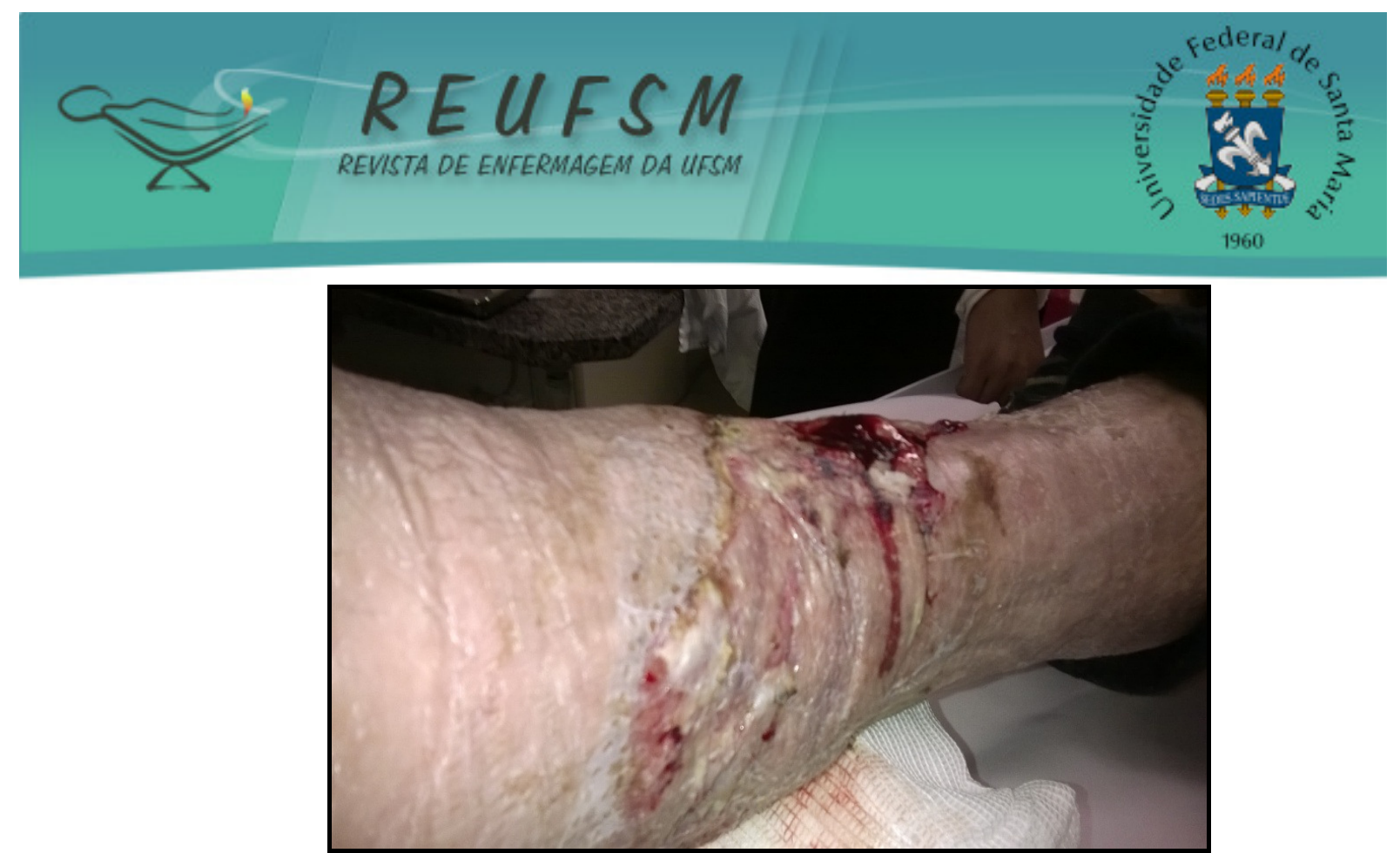

Figura 5 - Ferida operatória após autoenxertia cutânea 26/05/2014. Cascavel-PR, 2014.

\section{DISCUSSÃO}

A experiência com o uso da terapia por pressão negativa relatada neste estudo denotou importantes resultados no que concerne ao reparo tecidual de ferimentos complexos. Esta técnica apresenta-se como alternativa significativamente satisfatória, em comparação com técnicas tradicionais de curativos. ${ }^{6}$ Dentre as principais vantagens do uso desta modalidade terapêutica em hospitais, destacam-se a diminuição da morbidade, tempo de cicatrização das lesões e a diminuição de custos, tanto com as internações hospitalares quanto em relação à utilização de técnicas com produtos industrializados. ${ }^{7}$

No que diz respeito ao tempo de permanência do curativo por pressão negativa, houve variações de dois a três dias. Devido ao excesso de exsudação, nos primeiros quinze dias de instalação foram necessárias trocas diárias do curativo. Este tempo foi semelhante ao apresentado em estudo realizado no Japão com 14 pacientes, no qual os pesquisadores efetuaram troca da espuma em curtos períodos de tempo. ${ }^{8} \mathrm{Em}$ outro estudo, o tempo de permanência dos pacientes com o curativo a vácuo foi de pouco mais de oito dias. ${ }^{9}$

Estudos sobre terapia por pressão negativa têm apontado como complicações desta técnica, macerações da pele e formação de lesões bolhosas nos pacientes submetidos ao curativo a vácuo. ${ }^{8}$ Para prevenir tais complicações, salienta-se que a troca da espuma deve ser realizada a cada 5 a 7 dias para inspeção da lesão, ou sempre que ocorrer saturação da mesma, uma vez que após este processo, a força de pressão negativa é diminuída, podendo tornar-se nula. ${ }^{1-2} \mathrm{Com}$ a perda progressiva da pressão negativa, aumentam-se as chances de piora da lesão. Por outro lado, uma pressão muito elevada pode igualmente ocasionar bolhas ou lesão tecidual no leito ou nas bordas da ferida. Vale ressaltar, ainda, que a retirada das espumas deve ser feita de maneira gradual, a fim de evitar sangramento no leito da ferida e remoção mecânica do tecido de granulação. Além disso, é preciso promover conforto ao paciente, recomendando-se a infusão de medicamento analgésico para o controle da dor durante o procedimento. ${ }^{1}$

Embora sejam disponibilizados no mercado produtos específicos para tratamento de feridas, como a terapia por pressão negativa, tem-se como principal empecilho para o amplo uso destes produtos, o alto custo financeiro. ${ }^{10}$ No entanto, no que se refere ao impacto econômico da técnica artesanal, enfatiza-se que este estudo não realizou análise de custos. Contudo, infere-se que a terapia por pressão negativa, desenvolvida por método 


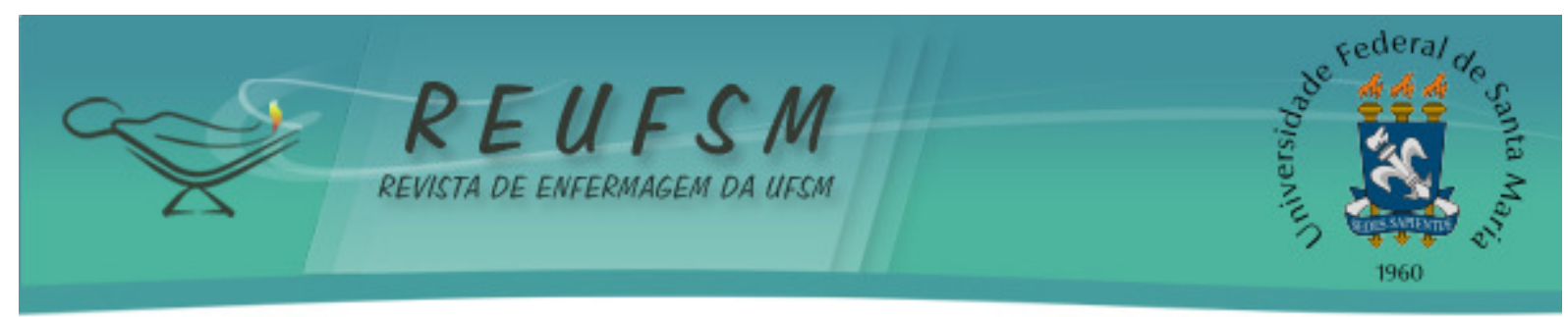

artesanal, pode apresentar custos significativamente mais baixos quando comparado com produtos comerciais sem, entretanto, deixar de apresentar benefícios semelhantes. ${ }^{11}$

Assim como em outras instituições públicas, o uso de produtos comerciais disponíveis no mercado mostrou-se inacessível, de modo que a técnica artesanal tem assumido importante papel no tratamento de feridas complexas na instituição aqui apresentada. ${ }^{10-11}$ Neste sentido, estudos sobre esta modalidade de tratamento, sejam em relação a técnicas artesanais ou industrializadas, são de fundamental importância, uma vez que comprovado seu custo-benefício e resultados, espera-se ampliar sua utilização e melhorar a acessibilidade destes produtos ao mercado. ${ }^{12}$

Acredita-se que, os benefícios da terapia por pressão negativa se devem ao seu mecanismo de ação o qual parece promover a "redução do edema intersticial, redução da infecção, stress mecânico e estímulo a angiogênese". 2:147 Estes mecanismos estão relacionados com a modulação inibitória de fluidos, depuração bacteriana e proliferação celular por meio do aumento do fluxo sanguíneo. ${ }^{2,12}$

Neste estudo, os curativos por pressão negativa foram orientados por enfermeiras integrantes da comissão de curativos, com experiência na avaliação e tratamento de feridas complexas e utilização de produtos e coberturas especiais. A experiência profissional, aliada à formação acadêmico-científica, tem contribuído sobremaneira na prática clínica diária do profissional de enfermagem. A existência de equipe multiprofissional foi igualmente positiva, tendo em vista que a discussão do caso entre a equipe objetivou encontrar e adaptar a melhor terapêutica ao paciente, por meio de abordagem integral. Neste sentido, o mesmo também recebeu acompanhamento clínico, psicológico e nutricional durante o período em que esteve internado.

\section{CONSIDERAÇÕES FINAIS}

O relato em questão mostrou que a utilização da técnica artesanal/não tecnológica do curativo por pressão negativa em ferida complexa, também permite resultados positivos quanto aos benefícios e objetivos citados na bibliografia, principalmente, no que tange à diminuição do exsudato e regeneração tecidual acelerada. Desse modo, considerou-se que a terapia por pressão negativa artesanal apresenta boa efetividade e eficácia, tornando-se, uma opção para instituições de saúde de pequeno e médio porte cujos recursos financeiros não favorecem a aquisição de modelos comerciais específicos para tal finalidade. No entanto, não foi possível estabelecer um comparativo com técnicas comerciais, devido à inexistência destas na instituição. Além disso, não foram contabilizados os custos para efetivar a técnica artesanal aqui apresentada, tornando-se estas, as principais limitações deste relato.

Nessa direção, faz-se necessário o desenvolvimento de estudos específicos no que diz respeito aos resultados e custos da terapia por pressão negativa, de forma que se possa estabelecer um comparativo em relação à realização destas técnicas distintas.

\section{REFERÊNCIAS}

1. Pérez AA, Romero GPM, Avila JMJ. Terapia de presión negativa como alternativa en el manejo de la infección em cirúrgia de columna. Coluna/Columna [Internet]. 2013 [acesso em 2014 ago 30];12(4): 330-3. Disponível em: http://www.scielo.br/pdf/coluna/v12n4/15.pdf.

2. Pereima MJL, Goulart BC, Pereima RR, Feijó R, Freitas JL. Diminuição do tempo de maturação de matrizes de regeneração dérmica quando associados ao uso de curativos de pressão negativa. Rev Bras Queimaduras [Internet]. 2013 [acesso em 2015 jun 


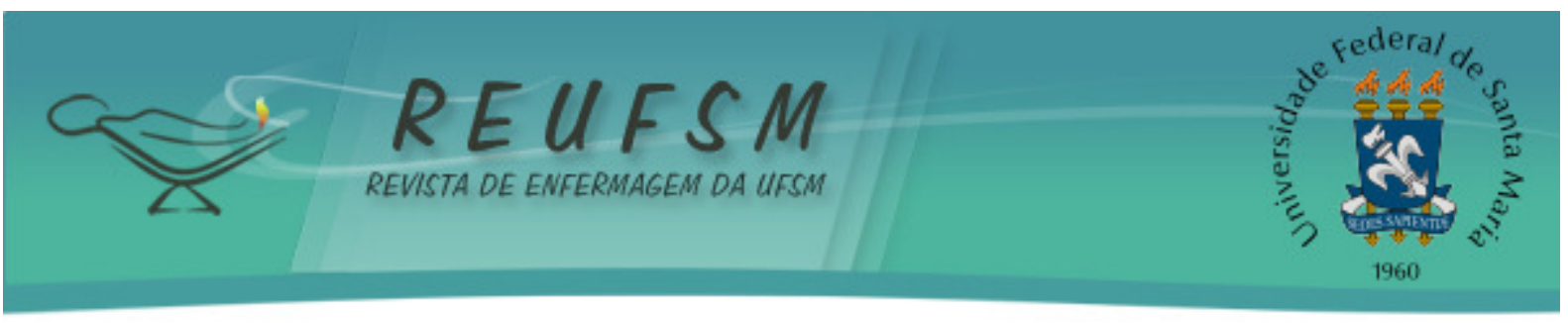

14];12(3):145-52. Disponível em: http://cepelli.com.br/wpcontent/uploads/2015/01/v12n3a04-9.pdf.

3. Franciosi LFN, Lucas LS, Vieira VRS, Castan MR, Souza MRP. O uso de curativos a vácuo como tratamento intermediário no trauma complexo de extremidade: experiência clínica e padronização da técnica. Arq Catarin Med [Internet]. 2010 [acesso em 2014 jul 15];39(2):56-60. Disponível em: http://www.acm.org.br/revista/pdf/artigos/801.pdf.

4. Neto-Rezende JB, Cunha-Melo JR, Andrade MV. Cobertura temporária da cavidade abdominal com curativo à vácuo. Rev Col Bras Cir [Internet]. 2007 [acesso 2015 jun 14];34(5):336-9. Disponível

em:

http:/ / www.scielo.br/readcube/epdf.php?doi=10.1590/S0100-

69912007000500011 \&pid=S0100-

69912007000500011\&pdf_path=rcbc/v34n5/v34n5a11.pdf\&lang=pt.

5. Ferreira AM, Rigotti MA, Pena SB, Paula DS, Ramos IB, Sasaki VDM. Conhecimento e prática de acadêmicos de enfermagem sobre cuidados com portadores de feridas. Esc Anna Nery [Internet]. 2013 [acesso 2015 jun 14];17(2):211-9. Disponível em: http://www.scielo.br/pdf/ean/v17n2/v17n2a02.pdf.

6. Vendramin FS, Franco D, Franco TR. Utilização do plasma rico em plaquetas autólogo nas cirurgias de enxertos cutâneos em feridas crônicas. Rev Bras Cir Plást [Internet]. 2010 [acesso em 2014 ago 10];25(4):589-94. Disponível em http://www.scielo.br/pdf/rbcp/v25n4/04.pdf.

7. Marques ADB, Oliveira LB, Mourão LF, Luz MHBA. A terapia por pressão negativa no tratamento de feridas: uma revisão sistemática da literatura. Rev Interd [Internet]. 2013 [acesso em 2014 jul 15];6(4):182-7. Disponível em: http://revistainterdisciplinar.uninovafapi.edu.br/index.php/revinter/article/view/225/pd f_82.

8. Faria Junior JA, Almeida CEF, Garcia FL, Lima RVKS, Marques RR, Cologna MHT. Tratamento multidisciplinar de feridas complexas. Proposta de Criação de "Unidade de Feridas" no Hospital das Clínicas da FMRP-USP. Editorial. Medicina [Internet]. 2013 [acesso em 2014 jul 15];46(4):355-60. Disponível em: http://revista.fmrp.usp.br/2013/vol46n4/Editorial\%20_Tratamento\%20multidisciplinar\%20 de\%20Feridas\%20Complexas.\%20Proposta\%20de\%20Cria\%E7\%E3o\%20de\%20\%93Unidade\%20de \%20Feridas\%94\%20no\%20HC-FMRP-USP.pdf.

9. Suzuki T, Minehara K, Matssura T, Kawamura T, Soma K. Negative-pressure wound therapy over surgically closed wounds in open fractures. J Orthop Surg [Internet]. 2014 [acesso em 2014 ago 10];22(1):30-4. Disponivel em: http://www.josonline.org/pdf/v22i1p30.pdf.

10. Kolios L, Kolios G, Beyersdorff M, Dumont C, Stromps J, Freytag S, et al. Cost analysis of Topical Negative Pressure (TNP) Therapy for traumatic acquired wounds. Ger Med Sci [Internet]. 2010 [acesso em 2014 ago 10];8:1-11. Disponível em: http://www.ncbi.nlm.nih.gov/pmc/articles/PMC2890208/pdf/GMS-08-13.pdf.

11. Milcheski DA, Ferreira MC, Nakamoto HA, Pereira DD, Batista BN, Junior PT. Uso da terapia por pressão subatmosférica em feridas traumáticas agudas. Rev Col Bras. Cir [Internet]. 2013 [acesso em 2014 ago 10];40(5):392-7. Disponível em: http://www.scielo.br/pdf/rcbc/v40n5/a08v40n5.pdf. 


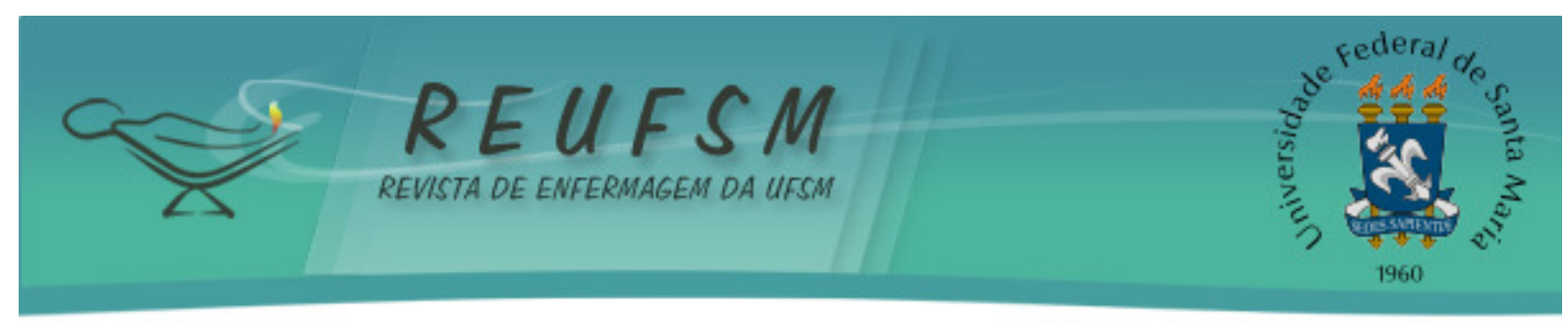

12. Moues CM, Heule F, Hovius SER. A review of topical negative pressure therapy in wound healing: sufficient evidence? The American Journal of Surgery [Internet]. 2011 [acesso em 2015 jun 14];201(4):544-56. Disponível em: http://ac.els-cdn.com/S0002961010006860/1s2.0-S0002961010006860-main.pdf?_tid=5cecc4a6-137e-11e5-be99-

00000aacb35d\&acdnat=1434387095_163042c902e747b568f6f7bd9b796ffd.

Data de recebimento: $24 / 10 / 2014$

Data de aceite: 20/07/2015

Contato do autor responsável: Reginaldo Passoni

Endereço postal: Rua Bela $\mathrm{n}^{\circ} 69$ apto. 03, Bairro Universitário, Cascavel, Paraná, Brasil, CEP: 85819-355.

E-mail: regi-pas@hotmail.com 